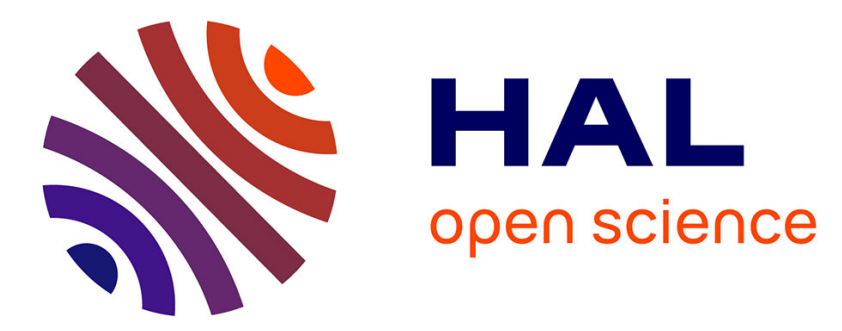

\title{
Einstein-Bohr recoiling double-slit gedanken experiment performed at the molecular level
}

X-J Liu, Q Miao, F Gel'Mukhanov, M Patanen, O Travnikova, C Nicolas, H Ågren, K Ueda, C Miron

\section{- To cite this version:}

X-J Liu, Q Miao, F Gel'Mukhanov, M Patanen, O Travnikova, et al.. Einstein-Bohr recoiling doubleslit gedanken experiment performed at the molecular level. Journal of Physics: Conference Series, 2015, 635 (11), pp.112063 10.1088/1742-6596/635/11/112063 . hal-01266793

\section{HAL Id: hal-01266793 \\ https: / hal.sorbonne-universite.fr/hal-01266793}

Submitted on 3 Feb 2016

HAL is a multi-disciplinary open access archive for the deposit and dissemination of scientific research documents, whether they are published or not. The documents may come from teaching and research institutions in France or abroad, or from public or private research centers.
L'archive ouverte pluridisciplinaire HAL, est destinée au dépôt et à la diffusion de documents scientifiques de niveau recherche, publiés ou non, émanant des établissements d'enseignement et de recherche français ou étrangers, des laboratoires publics ou privés.

\section{(c)(1)}

Distributed under a Creative Commons Attribution| 4.0 International License 
Einstein-Bohr recoiling double-slit gedanken experiment performed at the molecular level

This content has been downloaded from IOPscience. Please scroll down to see the full text.

2015 J. Phys.: Conf. Ser. 635112063

(http://iopscience.iop.org/1742-6596/635/11/112063)

View the table of contents for this issue, or go to the journal homepage for more

Download details:

IP Address: 134.157.80.136

This content was downloaded on 03/02/2016 at $12: 30$

Please note that terms and conditions apply. 
XXIX International Conference on Photonic, Electronic, and Atomic Collisions (ICPEAC2015) IOP Publishing Journal of Physics: Conference Series 635 (2015) 112063 doi:10.1088/1742-6596/635/11/112063

\title{
Einstein-Bohr recoiling double-slit gedanken experiment performed at the molecular level
}

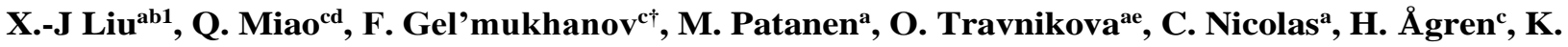 \\ Ueda $^{\mathrm{f}}$ and C. Miron ${ }^{\text {ag2 }}$
}

\begin{abstract}
${ }^{a}$ Synchrotron SOLEIL, Saint Aubin BP48, 91192 Gif-sur-Yvette Cedex, France ; ${ }^{\mathrm{b}}$ School of Physics, Beihang University, 100191, Beijing, China; ${ }^{\mathrm{c}}$ School of Biotechnology, Royal Institute of Technology, S-10691 Stockholm, Sweden; ${ }^{\mathrm{d} S h a n d o n g}$ University of Science and Technology, 266590, Shandong, China; ${ }^{\mathrm{e}}$ CNRS, Sorbonne Universités, UPMC Univ Paris 06, UMR 7614, Laboratoire de Chimie Physique-Matiére et Rayonnement, F-75005 Paris, France; ${ }^{\mathrm{f}}$ Institute of Multidisciplinary Research for Advanced Materials, Tohoku University, Sendai, 980-8577, Japan; ${ }^{\mathrm{g}}$ ELI-NP, Horia Hulubei National Institute for Physics and Nuclear Engineering, RO-077125, Romania.
\end{abstract}

\begin{abstract}
Synopsis Double-slit experiments illustrate proof for wave-particle complementarity. The essence of EinsteinBohr's debate about wave-particle duality was whether the momentum transfer between a particle and a recoiling slit could mark the path, thus destroying the interference. We realized this recoiling double-slit gedanken experiment by resonant X-ray photoemission from molecular oxygen for geometries near equilibrium (coupled slits) and in a dissociative state far away from equilibrium (decoupled slits). Interference is observed in the former case, while the electron momentum transfer quenches the interference in the latter case.
\end{abstract}

Einstein-Bohr recoiling double-slit gedanken experiment $[1,2]$ reveals one of the most impressive deviations from classical concepts. In a double-slit experiment one can infer that achieving information about the particle path via momentum transfer erases the interference pattern characteristic of the wave behavior [3]. However, when using macroscopic slits, momentum transfer from the particle to the slit is too small to be measured. For this reason, coherence and decoherence in double slit experiments have also been studied using ultra-light atomic slits.

Our experiment, based on resonant X-ray ionization of the $\mathrm{O}_{2}$ molecule (Fig. 1) using synchrotron radiation and a state-of-the-art coincidence set-up, offers the possibility to distinguish the momenta imparted to each of the two slits materialized by identical atomic sites: during the X-ray-induced ultrafast dissociation, the symmetry is broken owing to a site-dependent momentum exchange between the ejected electron and the dissociating molecule.

We demonstrate the occurrence of symmetry breaking in the dissociating $\mathrm{O}_{2}{ }^{+}$cation by a direct measurement of the momenta of co- and counter-propagating $\mathrm{O}+$ ions with respect to the ejected electron momentum. Which-path information (WPI) about the recoiling atomic slit is thus revealed, and the interference fringes are washed out through the measurement of the opposite Doppler shifts of two paths - the 'left' and 'right' dissociating oxygen ions.
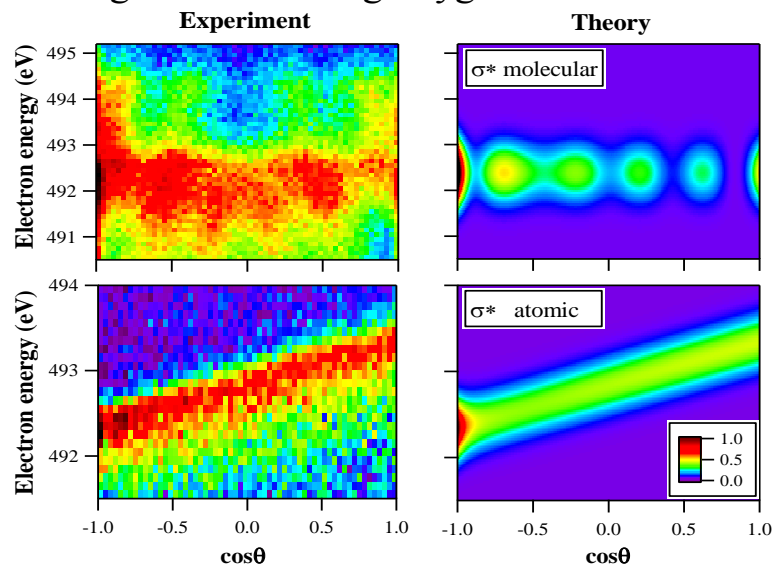

Figure 1. By both experiment and theory, the interference patterns show up when $\mathrm{O}_{2}$ molecular geometry near equilibrium (upper part), while they disappear when $\mathrm{O}_{2}$ dissociate far away from equilibrium(lower part).

We thus provide a consistent experimental proof and corresponding theoretical support showing a Doppler marker eliminates the interference pattern, in full agreement with Bohr's complementary principle [4].

\section{References}

[1] N. Bohr, in Quantum Theory and Measurement 9-49 (Princeton Univ. Press, 1983).

[2] W. K. Wootters et al 1979 Phys. Rev. D 19,473

[3] P. Bertet et al 2001 Nature 411, 166

[4] Liu, X.-J et al 2015 Nat. Photon. 9120 